\title{
Teach the Partnership: Critical University Studies and the Future of Service-Learning
}

\author{
David J. Fine \\ University of Dayton
}

Edward Zlotkowski's (1995) article "Does Service-Learning Have a Future?" challenges the academy to integrate community-engaged learning into the curriculum. As Zlotkowski suggests, students, staff, and faculty ought to engender a culture of civic action and ethical accountability enhanced by rigorous coursework, but this goal necessitates resources: administrators must invest in servicelearning to reap its full benefits. Issues arise, however, when one considers this investment in light of the academy's corporatization. Nussbaum (2010) has noted, for instance, how colleges and universities increasingly emphasize vocational training and professional readiness at the expense of humanist inquiry and civic responsibility. The academy's corporatization, she argues, threatens to erode the skills at the heart of democratic citizenship. Williams (2012) likewise censures this market-driven academy "with research progressively governed more by corporations that fund and benefit from it, with faculty downsized and casualized, and with students reconstituted as consumers subject to escalating tuition and record levels of debt" (p. 25). He insists that students, staff, and faculty must engage critically with these unsettling trends in higher education - an appeal, I argue, service-learning educators in particular must heed.

As higher education, deeply influenced by neoliberalism's pressures to marketize, adopts the structure and value systems of big business, it risks placing private interest before public concern. This danger, even more acute twenty-one years after the publication of Zlotkowski's article, underscores the need for a reassessment of the institutional means by which service-learning happens. "Perhaps," Zlotkowski (2015) wonders in his framing essay for the Future Directions Project, "there is a fundamental mismatch at the heart of our work that we have not wanted to recognize" (p. 84). Higher education may not prove the best location, after all, from which to effect progressive democratic change. In what follows, I stay the course with this provocation and argue that service-learning and community engagement (SLCE) educators must teach their partnerships - the specific histories, missions, and stakeholders involved - and thereby contextualize SLCE within the often problematic forces at work within and upon higher education. I thus call on the movement to interrogate, pedagogically, the motivations behind institutional "commitments" to SLCE and to account, ethically, for the economic and social privilege animating this service.

\section{Consider the Means}

To look back on the past twenty years and forward to the next is to acknowledge higher education's rapid corporatization and internationalization. I recommend that SLCE educators engage with the academy's globalization - the process whereby higher education assumes a corporate mentality and expands its reach internationally - by designing instruction in the vein of critical university studies (CUS). CUS is an emerging field that examines higher education in light of its history and cultural context. CUS analyzes both historical shifts in conceptions of the academy and contemporary issues such as adjunct labor and student debt, thereby "examining the university as both a discursive and material reality" (Williams, 2012, para.10). CUS is interdisciplinary by nature and gives students the opportunity to analyze both higher education and specific institutions through a lens that is particularly relevant given the current trends toward corporatization and internationalization. Indeed, conversations about their school's history, governance, and endowment position students, staff, faculty, and, especially in the case of SLCE, community members to think about the ethical dimensions of the academy's presence and impact in broader publics.

While this sort of dialogue may well happen in SLCE classrooms around the world, the explicit inclusion of CUS in SLCE programming aims to make these conversations more intentional and concrete. Through guided reflection on experiences in and with communities, facilitators prompt critical conversation about the deep interconnection between the institution and its community, emphasizing their shared history, economy, and 
space. Such dialogue accepts Williams' (2007) invitation to "teach the university" (p. 25); according to Williams, careful examination of higher education "gives students a language to articulate some of the stakes in current policies and practices, to define its cultural images, and to discern steps in its evolution" (p. 32). Students then bring this knowledge of higher education's history to bear on their own institution. At its best, a teach-the-university approach "sets out terms upon which to judge and assess particular incarnations of the university" ( $p$. 32). Within a CUS framework, SLCE educators not only approach colleges and universities as historical institutions - institutions that both shape and are shaped by the larger sweep of social and cultural forces - but also conceptualize SLCE as a distinct manifestation within that history. SLCE does not emerge in a vacuum. It participates in the adaptation and reinvention of institutions and is caught up in their missions, strategic plans, and promotional branding. CUS articulates these tensions and brings them to the table for ethical consideration.

Recognition of the academy as an evolving product of specific societal pressures is especially pressing as institutions globalize. Global engagement is, often enough, indicative of the profit-driven education that Keenan, SJ, decries (2015). For example, he cites how universities depend on the high tuition payments of international students to meet their budgets but fail to provide the support these students' academic and social flourishing requires. For reasons like these, Williams (2012) urges suspicion of "the globalization of higher education, which is promoted as altruistic but is often actually a profitseeking endeavor through which American or European universities sell their brands and services" (para. 21). As institutions progressively incorporate the language of global citizenship into their mission statements, they articulate a fundamental ambivalence. A tension exists between the call for moral reflection on human interconnection, on the one hand, and the promotion of economic globalization, on the other. This strain, of course, is not unfamiliar to SLCE practitioners. It appears as well in local settings, where SLCE activities can, as Zlotkowski (1995) warns, repackage a "missionary mentality" (p.130). To avoid positioning SLCE as a means of "saving" others and to acknowledge both professional and geographical privilege, SLCE educators must wrestle with the moral and political questions about the globalizing academy that CUS raises.

\section{Think the Process}

What might it look like to engage such questions as part of SLCE? At this juncture, I share an example of how my colleagues and I integrated CUS into an SLCE activity. During a January 2015 intersession trip to Cambodia - as part of Lehigh University's Global Citizenship (GC) Program - Professor Sothy Eng, Graduate Assistant Whitney Szmodis, and I designed, in close collaboration with long-term community partners, a layered SLCE experience to provoke reflection on global service-learning in general and on Lehigh's partnership with Caring for Cambodia (CFC) in particular. Lehigh University's College of Education has worked closely with CFC, an NGO dedicated to improving children's education, for many years. Professor Eng's graduate students visit CFC schools twice each academic year, and during the summer he directs a CFC-centered internship program for undergraduate and graduate students. Lehigh's seasoned partnership with CFC provided the Global Citizenship Program with the opportunity to structure a multifaceted experience at CFC schools. Its aim was both to provoke critical reflection on global citizenship in theory and practice and to provide valuable feedback to CFC on its attempts to strengthen volunteer programming as a means of promoting local Cambodians' agency.

During the intersession trip to Cambodia, GC students visited NGOs, attended court at the Khmer Rouge Tribunal, toured historical monuments, and dialogued with local university students. In advance of a half-day session at CFC, my colleagues and I divided the twenty-three participating GC sophomores into three teams. Each group visited a different CFC school and performed a distinct type of service. The first team - which included various student leaders on Lehigh's campus - undertook traditional volunteer work. They painted stools and assembled hygiene packets. They did not collaborate with CFC students, staff, or faculty directly; in this sense, the unglamorous labor was practical but isolated. The second group - composed of bilingual students and English-language learners - observed an English class. The GC students met with the instructor after class and shared their own experiences learning English. Here, they reflected with the instructor on what they had seen and heard during the class and offered feedback from their own perspectives. The third team interacted with Cambodian high school students. The high schoolers showed the GC students some traditional gardening methods and invited them to assist in planting a small garden patch. This interaction provided the Cambodian students with a chance to practice spoken English and to share their cultural knowledge. Significantly, it prioritized local knowledge and put the $\mathrm{GC}$ visitors in the position of learners.

By design, the GC students did not become aware of the differences among their experiences 
until later in the day. We invited the CFC curriculum director to join our nightly reflection, and she asked the GC students questions relevant to CFC's programming for international volunteers. As they wrestled with these questions, the students realized they had engaged in very different activities during the day. Through dialogue that drew on distinct forms of service, they began to articulate the larger stakes of their dissimilar experiences, posing questions of privilege and equity. They wondered if their visit interfered with the school day. They asked how long one must stay in order to make a positive contribution to the community. They probed the white-savior complex and problematized the good feelings obtained through one-anddone service. Along the way, they thought carefully about their university's relationship with the East, for each approach to service imagined a distinct relationship between Western travelers and native Cambodians. The visit's design allowed for differences in perspective among students, teachers, and partners to emerge organically, and these disparities invited GC students to come to their own individual conclusions regarding service-learning and their university's global engagement.

This activity thus foregrounded Lehigh's partnership with CFC as itself an object of study and critique. It highlighted the partnership's evolution over time as it demonstrated how the partnership continues to develop through negotiation with local and international partners. While it might seem like some students participated in the "better" service - perhaps the one that prioritized Cambodian students' knowledge - conversation highlighted benefits and costs to all three experiences. That particular morning, CFC needed stools painted and hygiene packets assembled. GC students in the first group were able to accomplish concrete tasks, freeing up CFC staff for other work. They responded, in short, to a need articulated by the partner. In contrast, a lot of thought and planning on behalf of CFC staff members went into organizing the other two experiences, time that might have been better spent on Cambodian - rather than GC - students. Further, as one GC student pointed out, CFC's engagement with GC students had larger consequences for its own branding, since CFC wants to communicate to its volunteers and donors the importance it places on native voice and experience. Points like these confronted students with SLCE's moral murkiness and entangled them in its thicket.

Clearly, our visit to CFC was far too short for a high-quality service experience. The visit sought, instead, to engage GC students and community partners in a critical conversation about possible - and competing - models for international part- nerships and future SLCE initiatives at CFC. These discussions continued in the Literature and Global Justice course that followed the two-week intersession trip. The GC students' experiences at CFC enriched their critical approach to literature and social justice as it grounded theoretical considerations in living partnerships and personal connections. In this way, our study of texts about colonial Indochina and from contemporary Southeast Asia - such as Graham Greene's The Quiet American and Vaddey Ratner's In the Shadow of the Banyan - remained in dialogue with the priorities of our home institution and the privilege lurking within abstract concepts like global citizenship. In their reflective writing and in classroom conversation, students situated their GC education in the concrete partnerships and privileges that made it possible in the first place.

\section{Evaluate the Ends}

This experience illuminates what I believe CUS offers to SLCE. While a CUS approach to SLCE reinforces SLCE's commitment to ongoing relationships, active reflection, and reciprocal exchange, it also underscores three benefits of teaching the partnership:

(a) A CUS approach grounds SLCE in the institutions that simultaneously support and thwart the movement's fruition. SLCE enhanced with a CUS framing sits with ambiguity and interrogates its own compromises, without sanitizing, idealizing, or infantilizing community members;

(b) CUS does not present higher education as an uncomplicated fount of truth from which good things inevitably flow, and it thus complicates SLCE educators' positions by defining them as embroiled in and sometimes in tension with systems larger than their individual research, teaching, and service (however progressive). Such candid recognition communicates to students the need for continued moral vigilance inside and outside the academy; and

(c) Finally, this method involves students directly in SLCE's thorny processes and thereby stimulates both critical reflection and judgment. It nudges learners beyond personal opinion to critical reflection and democratic interaction with peers, partners, and professionals as the learning community imagines situations from various perspectives and, given this diversity of viewpoints, judges a particular initiative's efficacy. 
In other words, CUS strategically implicates both individuals and communities in the moral muddle that is SLCE's relation to the global, corporate academy.

Analysis of a specific institution's history, governance, and outreach builds a solid, ethical foundation for SLCE initiatives moving forward. As we move in this direction, students might shift from being the recipients of prepackaged SLCE experiences - wherein, as Zlotkowski (1995) notes, "reflection too often amounts to little more than student 'discovery' of a pre-determined, ideologically 'correct' interpretation of the service experience" (p. 125) - to co-creators, who plan, implement, and evaluate initiatives in collaboration with campus facilitators and community partners. Thus, students - indeed all participants - might engage with SLCE's ethical complications rather than assuming, in advance, that all SLCE efforts are inherently good. For higher education's globalization affects more than service-learning abroad: SLCE must interrogate, with honesty and precision, the academic structures and institutionalized benefits that buttress its efforts. The mere appeal to prosocial, civic virtues belies the privilege of students, staff, and faculty housed in the powerful, neoliberal institutions of U.S. higher education. Resources, however necessary, are not innocent. I hence call for the SLCE movement to adopt a CUS approach, one that critically assesses the academy's past, present, and future engagements.

\section{Note}

I would like to thank the editors for their generous and helpful feedback on previous drafts. I am especially grateful for Patti Clayton's attention to little words, because they make a big difference. I also wish to thank my dear friends, Jenna Lay and Emily Shreve, who both read this essay and offered comments. My most sincere gratitude belongs, however, to Whitney Szmodis, who first theorized and subsequently orchestrated GC's visit to CFC. This piece, while expressing my personal views on higher education and SLCE, has benefitted by Whitney's commitment to ethical and passionate engagement with others.

\section{References}

Keenan, J. F. (2015). University ethics: How colleges can build and benefit from a culture of ethics. Lanham, MD: Rowman \& Littlefield.

Nussbaum, M. C. (2010). Not for profit: Why democracy needs the humanities. Princeton, NJ: Princeton University Press.

Williams, J. J. (2007). Teach the university. Pedagogy: Critical Approaches to Teaching Literature, Language, Composition, and Culture, 8(1), 25-42.

Williams, J. J. (2012, February 19). Deconstructing academe: The birth of critical university studies. The Chronicle of Higher Education. Retrieved from http:// chronicle.com

Zlotkowski, E. (1995). Does service-learning have a future? Michigan Journal of Community Service Learning, 2(1), 123-133.

Zlotkowski, E. (2015). Twenty years and counting: A framing essay. Michigan Journal of Community Service Learning, 22(1), 82-85.

\section{Author}

DAVID J. FINE (dfine1@udayton.edu) is an assistant professor of English with specialization in literature, culture, and religion at the University of Dayton. Formerly, he served as the assistant director of Lehigh University's Global Citizenship Program. His research, teaching, and service explore the interface of literature, ethics, and community engagement. 